\title{
Benchmark reoperative mitral surgery: There is room for improvement
}

\author{
Eugene A. Grossi, MD, and Mathew R. Williams, MD
}

From the Department of Cardiothoracic Surgery, NYU-Langone Medical Center, New York, NY.

Disclosures: Authors have nothing to disclose with regard to commercial support.

Received for publication March 18, 2018; accepted for publication March 21, 2018

Address for reprints: Eugene A. Grossi, MD, Department of Cardiothoracic Surgery, NYU-Langone Medical Center, 530 First Ave, Suite 9V, New York, NY 10016 (E-mail: eugene.grossi@nyumc.org).

J Thorac Cardiovasc Surg 2018;156:610

$0022-5223 / \$ 36.00$

Copyright (c) 2018 Published by Elsevier Inc. on behalf of The American Association for Thoracic Surgery https://doi.org/10.1016/j.jtcvs.2018.03.078

"Never measure the height of a mountain until you have reached the top. Then you will see how low it was."

$$
\text { — Dag Hammarskjold }
$$

In this issue of the Journal, Kaneko and colleagues ${ }^{1}$ review a 24-year experience at Brigham and Women's Hospital of more than 500 redo mitral operations and, from within, select a benchmark cohort based on compatibility with current transcatheter mitral valve-in-valve/ring (TMVIV/R) replacement therapies. Although overall operative mortality was $7.1 \%$ overall, in the Benchmark cohort the Society of Thoracic Surgeons Predicted Risk of Mortality was 6\% and observed mortality was $4 \%$. Major morbidities included permanent stroke at $4.1 \%$, reoperation for bleeding at $2 \%$, and re-redo valve at $1.4 \%$. Long-term survival in the overall experience was $75 \%$ survival at 5 years with the usual villains of increased age, renal impairment, endocarditis, and previous mitral valve replacement being predictors of poor long-term survival. The authors discuss that "despite the encouraging results of TMVIV/R, an indepth assessment of this technology is extremely crucial, especially in the context of limited long-term data."

We agree with the authors that redo mitral valve replacement can be performed safely in these patients qualifying for the benchmark cohort; this does give us insight as to a "gold standard" approach for the current era. The authors correctly discuss the report by Yoon and colleagues ${ }^{2}$ of TMVIV/R in 248 patients (Society of Thoracic Surgeons

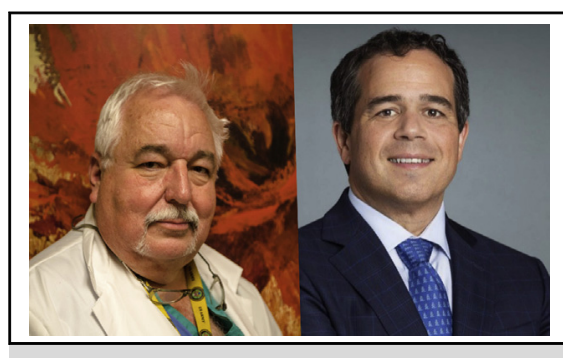

Eugene A. Grossi, MD, and Mathew R. Williams, MD

Central Message

Reoperative mitral valve surgery has 75\% 5year survival in this benchmark analysis. Can transcatheter techniques for valve-in-valve or valve-in-ring offer fewer complications and better long-term outcomes?

See Article page 619

Predicted Risk of Mortality 8.9\%) with 1-year all-cause mortality rates of $28.7 \%$ in the valve-in-ring group compared with $12.6 \%$; with the valve-in-valve group.

The take-home message is that postprocedural survival may be the ultimate reason for selecting one approach over another. With approximately $25 \%$ of mitral reoperations being performed for endocarditis, there will still unfortunately be extensive surgical work for this complex procedure.

\section{Reference}

1. Ejiofor JI, Hirji SA, Ramirez-Del Val F, Norman AV, McGurk S, Aranki SF, Shekar PS, Kaneko T. Outcomes of repeat mitral valve replacement in patients with prior mitral surgery: A benchmark for transcatheter approaches. J Thorac Cardiovasc Surg. 2018;156:619-27.

2. Yoon SH, Whisenant BK, Bleiziffer S, Delgado V, Schofer N, Eschenbach L, et al. Transcatheter mitral valve replacement for degenerated bioprosthetic valves and failed annuloplasty rings. J Am Coll Cardiol. 2017; 70:1121-31. 